\title{
A Plant Growth Simulation Algorithm for for Time-table Problems
}

\author{
Zhengwei Wang,a $\quad$ Yueguang $\mathrm{Li}^{2, \mathrm{~b}}$ \\ ${ }^{1}$ Gansu Normal University for Nationalities, Hezuo, gansu, 747000, \\ China \\ ${ }^{2}$ Gansu Normal University for Nationalities, Hezuo, gansu, 747000, \\ China \\ ${ }^{a}$ Yueguangli7@163.com, ${ }^{b}$ Yueguangli7@sohu.com
}

\begin{abstract}
Time-table Problem of universities is a many factor of the global optimization problem. In this paper, according to the characteristics of time-table problem, a Plant Growth Simulation Algorithm(PGSA) was put forward, and it was used to solve the Time-table Problem, the algorithm was experimented and the experimental results show that the new algorithm has reliable convergence, high convergence rate and solution precision.
\end{abstract}

Keywords: Plant Growth Simulation Algorithm(PGSA); Time-table Problem; NP- complete problem; Intelligent algorithm

\section{Introduction}

Time-table Problem of Universities is a many factor of the global optimization problem, it is a NP- complete problem ${ }^{[1]}$. Since Time-table Problem of Universities involved in many information, the methods for Time-table Problem of Universities are the classical algorithm, structure algorithms and intelligent optimization algorithms. Among them, the classical algorithms, such as branch and bound method, dynamic programming method the exact solutions of problems can be obtained, but the classical algorithms are limited by the problem size and computing complexity, only suitable for solving small problems. Constructive algorithms, such as NEH method, Rajendran method, the methods 
can set up the problem of scheduling solution quickly, but the structure complex, and usually the solution quality is poor. Intelligent optimization algorithms, such as genetic algorithm ${ }^{[2]}$, ant colony algorithm ${ }^{[3]}$, particle swarm optimization algorithm ${ }^{[4]}$, immune algorithm ${ }^{[5]}$ and a variety of hybrid algorithm etc ${ }^{[6]}$. The intelligent algorithms have been paid more and more attention, they are used to solve combinatorial optimization and $\mathrm{NP}^{[7]}$.The optimization algorithms have respective advantages and defects, some fast operation but needs computer storage capacity, some need a computer memory but a small amount of computation time is too long, some fast operation but solving city small scale ${ }^{[8]}$. In order to solve the above problems, this paper puts forward a Plant Growth Simulation Algorithm(PGSA) to solve Time-table Problem of Universities.

\section{The plant growth simulation algorithm}

Plant growth simulation algorithm(PGSA) is an evolutionary computation technique through simulating the growth processes in plants, which is based on the principles of plant phototropism growth ${ }^{[9]}$. The algorithm has a good prospect in the application due to requiring a simple on the parameters. It has gradually been applied in the field of engineering by many scholars ${ }^{[10]}$.

Plants can be viewed as a system, which composes of a large number of branches and nodes. It must be as soon as possible to strive for breeding more branches and leaves for earning more surface areas, which can obtain the greatest possible sunlight. The form of grammar that simulates the plant description analysis and development had been established since linguistics was introduced into the biological, which based on a simple rewrite rules and branching rules, this is called L-system. Formal description of plant growth can be carried out as the following:

1. The section of the site grow new branches which first emerged in a number of stems is called the growth node.

2. Most of the new branches have grown updated branches, and the process repeated on the old and new branches.

3. Different branches in the tree have similarities with each other, and the entire plant has self-similar structure. 
The Branching model of plant growth is improved according to L-system combined with computer graphics and fractal theory, the plant, as the form of plant growth characteristics, can be described as follow: Supposed branches of plant growth occurred in the two-dimensional plane, Each branch growing in units length every time, or rotating a certain angle $\alpha$, Starting from the node of trunk or branches, The growth process were repeated through rewriting the rules of branches of plant growth in the two dimensional plane.

It was proved by biological experiments that a new branch that is able to grow depends on its morphactin concentration when the plant has more than one node. The node which has larger value of morpheme concentration has more growth opportunities than the smaller one, morphactin concentration are not pre-assigned to the nodes, but formed according to their location information which we call that plant showed the feature of plant's Phototropism. After the node has been formed, morphactin concentration will be readjusted according to changing in the environment of a new growth node else.

We could describe the characteristics of plant growth in term of the mathematical view basis on plant growth analysis of the above. Suppose the length of tree trunk is $\mathrm{T}$, the length of branch is $\mathrm{L}$, there are $\mathrm{W}$ growing nodes $S_{T}=\left(S_{T 1}, S_{T 2}, \ldots, S_{T W}\right)$ in the trunk, morphactin concentration of those nodes is $P_{T}=\left(P_{T 1}, P_{T 2}, \ldots, P_{T W}\right) \quad$ respectively. There are $q$ growth nodes $S_{T}=\left(S_{T 1}, S_{T 2}, \ldots, S_{T q}\right)$ in the branch. Morphactin concentration of those nodes is $P_{T}=\left(P_{T 1}, P_{T 2}, \ldots, P q\right)$ respectively. The morphactin concentration which grown in the trunk and branch is calculated as follows:

$$
P_{T i}=f\left(x_{0}\right)-f\left(S_{T i}\right) / \sum_{i}^{W}\left(f\left(x_{0}\right)-f\left(S_{T i}\right)\right)+\sum_{j}^{q}\left(f\left(x_{0}\right)-f\left(x_{T q}\right)\right)
$$

Where $x_{0}$ represents the root of plant (the initial node), $f(*)$ is the information function of the node in the environment, The smaller value of the function as possible shows the better environment where the node located, it will help to grow new branch. 
From formula (1), the value of morphactin concentration in every node depends on relative position of the relative to the initial root and the location of the environmental information, the mechanism consistent with the formation of the morphactin concentration in the plant cell. We can deduced from formula (1) as follows:

$$
\sum_{i=1}^{T} \sum_{j=1}^{q}\left(P_{T i}+P_{T j}\right)=1
$$

We can produce random number in the interval $[0,1]$. The random number must fall within one of the state space $\left(P_{1}, P_{2}, \ldots, P_{T+q}\right)$, where the corresponding node will have a prior right to grow new branch. A simple example of morphactin concentration state space displays in the fig. 1.The value of morphactin concentration in all nodes will change after the new branch has grown up. Computation formula of the value of morphactin concentration in other nodes will add the relevant node on the new branch, and remove the grown node, which basis on formula (1). The process will be repeated until there is no new branches growing.

\section{The analysis of simulation}

The following, Department of Computer Science of Gansu Normal College for Nationalities (4grade,12 classes,30 teachers,15class) as an example to test, and record test results, the actual inspection generation schedule, no case of conflict. Table 1 presents the Comparison of this algorithm and ant colony algorithm. We can see that the algorithm is better than ant colony algorithm. Figure 2 presents the probability curves of finding in the iterative process. Figure 3 presents the curves of step factor in the iterative process. 
Table 1 the Comparison of this algorithm and ant colony algorithm

\begin{tabular}{|c|c|c|c|c|}
\hline Algorithm & Test times & $\begin{array}{c}\text { The number } \\
\text { of } \\
\text { successful }\end{array}$ & $\begin{array}{l}\text { The } \\
\text { probability of } \\
\text { success }\end{array}$ & $\begin{array}{c}\text { Average time } \\
\text { (s) }\end{array}$ \\
\hline $\begin{array}{c}\text { Ant colony } \\
\text { algorithm }\end{array}$ & 100 & 80 & $80 \%$ & 26 \\
\hline $\begin{array}{c}\text { Algorithm } \\
\text { of the paper }\end{array}$ & 100 & 95 & $95 \%$ & 12 \\
\hline
\end{tabular}

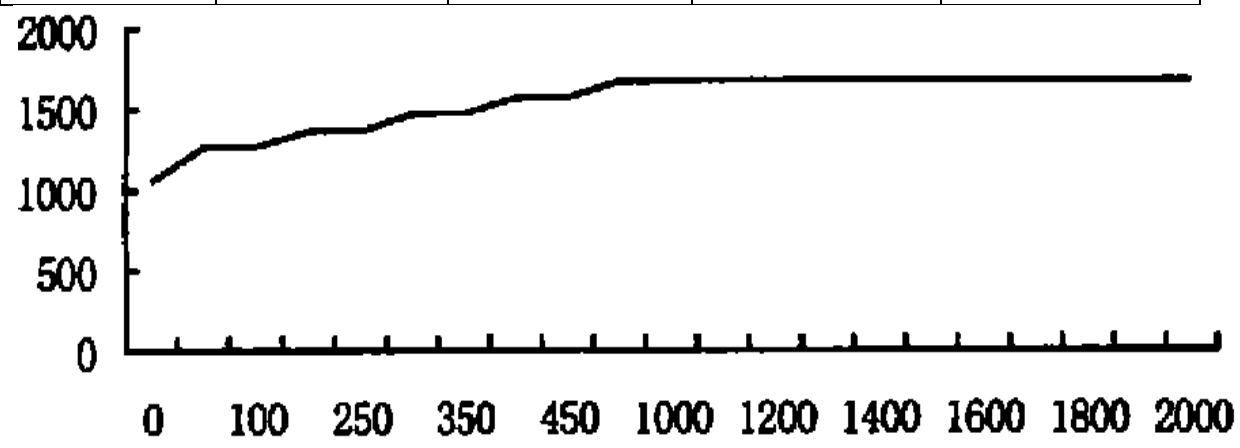

Figure 1 the probability curves of finding in the iterative process

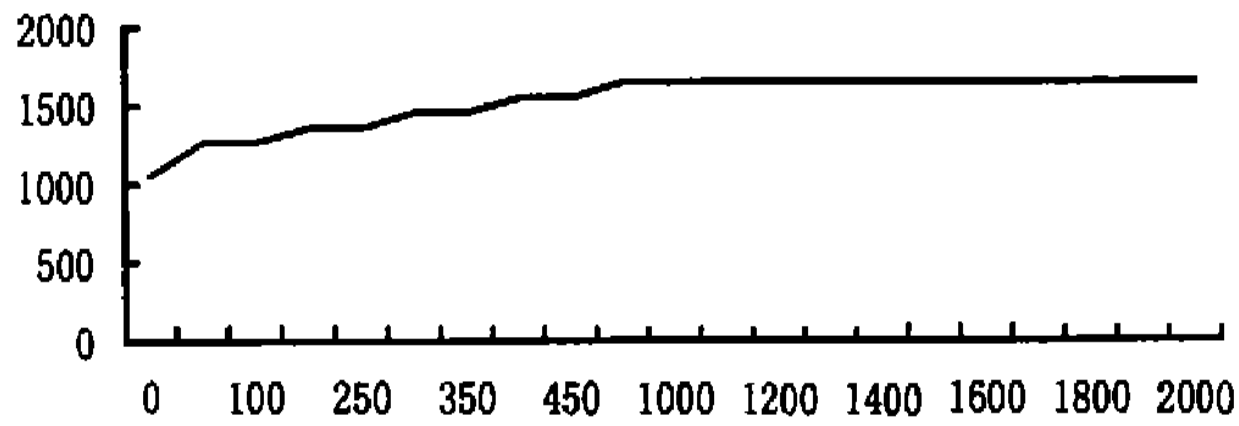

Figure 2 the curves of step factor in the iterative process

\section{Conclusions}

This paper proposes a plant growth algorithm, the plant growth algorithm is applied to solve Time-table Problem of universities, the performance has been improved obviously, and as the problem size increases, the improvement is more 
obvious. Experiments show that, the new algorithm has strong global search ability, convergence speed and solution accuracy of plant growth algorithm is high.

\section{Acknowledgment}

This work is supported by Dean Fund of Gansu Normal College for Nationalities.

\section{References}

[1] Garey M R, Johnson D S. Computers and Intractability: A Guide to the Theory of NP-Completeness[M]. San Franciso,CA: Freeman,4,109-122(1979).

[2] Holland J H. Genetic Algorithms and the Optimal Allocation of Trials [J]. SIA M J Computer, 1973: 2 (2): 89-104.

[3] Colorni A, Dorigo M, Maniezzo V. Distributed Optimization by Ant Colonies[A] . Proc 1st European Conf Artificial Life Plans[C]. France: Elsevier, 1991: 134-142.

[4] Eberhart R, Kennedy J. A New Optimizer Using Particles Swarm Theory[A]. Proc 6th Int Symposium on Micro Machine and Human Science[C]. Nagoya: IEEE Service Center, Piscataway, 1995: 39-43.

[5] Dasgupta D, Forrest S. Artificial Immune Systems and Their Applications [M]. Berlin: Spring-Verlag, 1998:267-277.

[6] Wang L. Intelligent Optimization Algorithms Applications [M]. Beijing: Tsinghua University Press,2001.

[7] Reingold. E. M. J. Neivergelt and N. Deo. Combinatorial Algorithms: Theory and practice Prentice-Hall ,Englewood cliffs, NJ(1977).

[8] Han K2H . Genetic quant um algorithm and its application to combinatorial optimization problem / / Proceedings of IEEE the 2000 Congress on Evolutionary Computation . San Diego , USA, IEEE Press , 2000 : 1354-1360. 
[9] Li T,Wang C F ,et al.A global optimization bionics algorithm for solving integer Programming plant growth simulation algorithm[J] .Systems Engineering - Theory \& Practice ,2005,25(1) :76 - 85.

[10] Li T, Wang $\mathrm{Z} \mathrm{t}$. Application of plant growth simulation algorithm on solving facility location problem [J]. Systems Engineering - Theory \& Practice, 2008, (12):107-115 